\title{
Management of Daylily Rust with Different Fungicide Combinations and Spray Intervals
}

R. S. Emmitt, Department of Plant Pathology, University of Georgia, Griffin Campus, Griffin 30223; K. L. Stevenson and T. B. Brenneman, Department of Plant Pathology, University of Georgia, Tifton Campus, Tifton 31793; and J. W. Buck, Department of Plant Pathology, University of Georgia, Griffin Campus

\begin{abstract}
Emmitt, R. S., Stevenson, K. L., Brenneman, T. B., and Buck, J. W. 2016. Management of daylily rust with different fungicide combinations and spray intervals. Plant Dis. 100:188-191.

Daylily (Hemerocallis spp.) is a popular herbaceous perennial plant and was considered to be relatively disease free until 2000 , when daylily rust, caused by Puccinia hemerocallidis, was first detected in the United States. Management of daylily rust in nurseries is dependent on the use of fungicides, which are typically applied to the foliage of large blocks of plants at 21- or 28-day intervals. The objectives of this study were to determine the most effective fungicides or fungicide combinations and application intervals for managing daylily rust in the field. Foliar sprays of azoxystrobin alone at 14-, 21-, or 28-day intervals, combinations of azoxystrobin + propiconazole, azoxystrobin + chlorothalonil, propiconazole + chlorothalonil, and chlorothalonil + thiophanatemethyl applied at intervals of 21 or 28 days, and a nontreated control were evaluated under high disease pressure, at three locations in Griffin, GA in

2014. In all three fields, all treatments that included azoxystrobin were effective at reducing area under the disease progress curve (AUDPC) compared with the nontreated control. At two of the three locations, azoxystrobin applied at 14-day intervals had significantly lower AUDPC than when applied at 21- or 28-day intervals. The addition of propiconazole or chlorothalonil to azoxystrobin did not improve rust control. Disease ratings for propiconazole + chlorothalonil and thiophanate-methyl + chlorothalonil applied at 21- or 28-day intervals did not differ from the untreated control. The 21-day treatments resulted in significantly lower disease than 28-day treatments (all fungicides) in the middle and end of the season. Elimination of less efficacious active ingredients and unnecessary applications can help growers maximize profitability by reducing expenses as well as simplifying fungicide inventory and storage.
\end{abstract}

Daylily rust, caused by the fungus Puccinia hemerocallidis (Thüm.), has become an increasing problem for daylily growers since its introduction into the United States in 2000 (Williams-Woodward et al. 2001). Symptoms on daylily foliage include initial chlorotic spots that become orange, spore-producing lesions followed by foliage dieback. Infected plants are typically unmarketable and daylily rust can cause significant, negative effects on the ornamental market in the United States which was valued at $\$ 602$ million in 2013 (United States Department of Agriculture 2014).

Daylily plants (Hemerocallis spp.), are native to Asia and are one of the most widely cultivated plants in the world (Gatlin 1999). They were considered to be relatively disease and pest free in the United States until daylily rust arrived (Williams-Woodward and Buck 2002). P. hemerocallidis was initially detected in the southeastern U.S. states of Florida, Georgia, South Carolina, and Alabama (Williams-Woodward et al. 2001). In 2000, P. hemerocallidis was placed under state and federal quarantine; the resulting stop-sale orders and destruction of infected plant materials were very costly to growers. In 2003, daylily rust was officially reported in 24 states and unofficially in 9 more and the federal quarantine was lifted (Buck and Ono 2012). P. hemerocallidis is currently considered endemic in the United States in all United States Department of Agriculture hardiness zones 7 or greater (Wise et al. 2004).

Host resistance to $P$. hemerocallidis has been observed in Hemerocallis spp. Of the 84 commercially important daylily varieties assessed for resistance in greenhouse assays, $14(17 \%)$ were resistant, $13(15 \%)$ were mildly resistant, $22(26 \%)$ were mildly susceptible, and 37 (44\%) were susceptible (Mueller et al. 2003). There are nearly 80,000 daylily cultivars registered with the American Hemerocallis

Corresponding author: J. W. Buck; E-mail: jwbuck@uga.edu

Accepted for publication 26 June 2015.

http://dx.doi.org/10.1094/PDIS-06-15-0648-RE

(C) 2016 The American Phytopathological Society
Society and the phenotype for most cultivars is unknown. Pathotypes (races) of $P$. hemerocallidis were identified in the southeastern United States, suggesting that host resistance could be overcome by the fungus (Buck 2013). Of the 19 cultivars tested, 15 expressed differential resistance to 16 isolates of $P$. hemerocallidis.

Fungicides remain the most effective method for managing daylily rust. Fungicides with active ingredients from several fungicide classes are currently labeled for the management of daylily rust. Products are available for both commercial growers and homeowners to be used in rotation on 7-, 14-, 21-, or 28-day intervals (Buck and Ono 2012; Williams-Woodward 2015). Many commercial growers apply fungicides at 21- or 28-day intervals over large blocks of multiple species and many provide excellent rust control (Buck and Williams-Woodward 2003; Buck and Youmans 2009; Dong et al. 2013; Mueller et al. 2004). Azoxystrobin or pyraclostrobin (Fungicide Resistance Action Committee [FRAC] group 11); chlorothalonil (FRAC group M5); myclobutanil, propiconazole, triadimefon, or tebuconazole (FRAC group 3); and flutolanil (FRAC group 7) all give some level of control when applied prior to disease onset. Azoxystrobin, chlorothalonil, myclobutanil, propiconazole, and triadimefon reduced lesion development by $P$. hemerocallidis on daylily when applied as foliar sprays up to 15 days prior to inoculation while azoxystrobin significantly reduced lesion formation when applied 7 days after inoculation (Mueller et al. 2004). Azoxystrobin was also shown to significantly reduce disease severity for up to 9 weeks postapplication when used as a root dip and as a single soil drench treatment (Dong et al. 2013). Azoxystrobin, chlorothalonil, flutolanil, mancozeb, propiconazole, and triadimefon each significantly reduced lesion formation by $P$. hemerocallidis when assessed 15 days postinoculation (Buck and WilliamsWoodward 2003). In this greenhouse study, fungicides were applied as foliar sprays $24 \mathrm{~h}$ prior to inoculation and results were consistent across the five trials.

Currently, growers, hybridizers, and homeowners have no definitive chemical combination or application interval for the management of daylily rust. Although many chemicals and application intervals are recommended, the elimination of the least effective treatment program can help growers to maximize profitability and 
decrease applicator exposure. The objectives of this study were to determine the most effective timing intervals and chemical combinations for managing daylily rust on field-grown daylily plants.

\section{Materials and Methods}

Daylily field plantings. Field trials were conducted in 2014 at the Griffin campus of the University of Georgia on Cecil sandy clay loam (pH 6.2, 1.9\% organic matter). Three separate fields were used for this study: field 1 is approximately $1.6 \mathrm{~km}$ from field 2 and approximately $2.4 \mathrm{~km}$ from field 3; field 2 is approximately $0.8 \mathrm{~km}$ from field 3 . Field 3 and all plants within were used in field trials conducted in 2010 and 2011 (Dong et al. 2013). Fields 1 and 2 were cultivated and planted 2 weeks apart in May 2014 using bare-root plants of the rust-susceptible 'Pardon Me' (Mueller et al. 2003). All study areas were covered with weed barrier fabric (Greenscapes Inc., Calhoun, GA) prior to planting and covered with 5 to $10 \mathrm{~cm}$ of pine bark mulch after planting. Plants were irrigated as needed and fertilized with 10-10-10 water-soluble fertilizer (Farmer's Favorite Fertilizer, Evergreen, $\mathrm{AL}$ ) at $5.7 \mathrm{~kg} \mathrm{ha}^{-1}$ every 2 months. Weeds were managed with label rates of Gly Star Plus (Albaugh LLC, St. Joseph, MS) nonselective glyphosate herbicide and SedgeHammer (halosulfuron-methyl; Gowan Turf and Ornamental, Yuma, AZ).

Experimental design and fungicide treatments. The experiment was conducted in three fields, each of which consisted of 144 plants arranged in 12 rows of 12 plants each, spaced $0.6 \mathrm{~m}$ within rows and $1.0 \mathrm{~m}$ between rows. Each row was divided into four replications (experimental units) consisting of three consecutive plants. In total, 432 plants were evaluated in this study. The experimental design was completely randomized, with 11 fungicide treatments and one untreated control, each replicated four times. Treatments were randomly assigned to experimental units within each field using Agricultural Research Manager software (Gylling Data Management Inc., Brookings SD). In all, 36 daylily (Pardon Me) plants in 5.7-liter containers were inoculated with $P$. hemerocallidis isolate Grif 2 (Buck 2013; Buck et al. 2010) and kept in a greenhouse for 3 weeks. In June 2014, 12 rust-infected daylily plants were planted into each field. Infected daylily plants were spaced evenly throughout each field and planted between rows.

Label rates of azoxystrobin (Heritage 50 WDG; Syngenta Crop Protection Inc., Greensboro, NC) at $0.32 \mathrm{ml} \mathrm{liter}^{-1}$, propiconazole (Banner MAXX 14.3 MEC; Syngenta Crop Protection Inc.) at $0.62 \mathrm{ml} \mathrm{liter}^{-1}$, chlorothalonil (Daconil Ultrex 82.5 WDG; Syngenta Crop Protection Inc.) at $1.60 \mathrm{~g} \mathrm{liter}^{-1}$, and thiophanate-methyl (Clearys
3336 F; Cleary Chemical Corporation, Dayton, NJ) at $0.94 \mathrm{ml} \mathrm{liter}^{-1}$ were applied as foliar sprays. Azoxystrobin alone was applied at 14-, 21-, and 28-day intervals. In addition, azoxystrobin was applied in combination with either propiconazole or chlorothalonil at 21- and 28-day intervals. Propiconazole was applied in combination with chlorothalonil at 21- and 28-day intervals and chlorothalonil + thiophanate-methyl at 21- and 28-day intervals. All fungicide treatments began on 3 July 2014. The 14-day treatment was applied eight times. The 21-day treatments were applied six times and 28-day treatments were applied four times throughout the growing season. All fungicides were applied using a $\mathrm{CO}_{2}$-pressurized $(276 \mathrm{kPa})$ backpack sprayer using a single flat-fan air-induction nozzle (11002VS; TeeJet Technologies, Wheaton, IL). Initially, a volume of $250 \mathrm{ml}$ of fungicide was applied to each experimental unit of three daylily plants and each plant was sprayed until runoff. The volume of fungicide solution required to wet the foliage in each block was increased during the experiment as the plants grew larger.

Data collection and analysis. Rust was assessed weekly for 12 weeks starting from the first appearance of widespread symptoms on the nontreated controls (31 July), which was approximately 4 weeks after the first fungicide application. Disease intensity was assessed on a 0 -to- 5 rating scale, where $0=$ no lesions, $1=1$ to 20 lesions per leaf on old leaves, $2=>20$ lesions per leaf on old leaves, $3=1$ to 20 lesions per leaf on new leaves, $4=>20$ lesions per leaf on new leaves, and $5=>20$ lesions on every leaf (Dong et al. 2013). The youngest third of leaves on the plant were considered new leaves. All remaining leaves were considered old leaves. For each location, disease ratings from all dates were used to calculate area under the disease progress curve (AUDPC) to examine treatment effects through the season. AUDPC values were calculated 4, 8, and 12 weeks after rust symptoms were first observed. AUDPC values were analyzed using PROC MIXED of SAS (version 9.4; SAS Institute, Cary, NC) statistical software. Single-degree-of-freedom linear contrasts were calculated to compare specific groups of treatments.

\section{Results}

There were significant $(P<0.05)$ field-treatment interactions on AUDPC; therefore, data from individual fields are presented separately. Disease pressure was high in all three fields, with severity ratings on the nontreated control plants reaching 5.0 (>20 lesions on all leaves) on 24 September, 17 September, and 23 October in fields 1, 2 and 3, respectively.

All azoxystrobin treatments were effective at reducing disease severity compared with the nontreated control at 4,8 , and 12 weeks

Table 1. Daylily rust area under the disease progress curves (AUDPC) for plants in three fields treated at 14-, 21- or 28-day application intervals with different fungicides and fungicide combinations ${ }^{\mathrm{x}}$

\begin{tabular}{|c|c|c|c|c|c|c|c|c|c|}
\hline \multirow[b]{3}{*}{ Fungicide $^{z}$} & \multicolumn{9}{|c|}{ AUDPC (date) $)^{\mathbf{y}}$} \\
\hline & \multicolumn{3}{|c|}{ Field 1} & \multicolumn{3}{|c|}{ Field 2} & \multicolumn{3}{|c|}{ Field 3} \\
\hline & 21 Aug & 24 Sep & 23 Oct & 21 Aug & 24 Sep & 23 Oct & 21 Aug & 24 Sep & 23 Oct \\
\hline Az 14-day & $0.8 \mathrm{~d}$ & $6.1 \mathrm{e}$ & $16.9 \mathrm{~d}$ & $4.2 \mathrm{~b}$ & $6.3 \mathrm{e}$ & $21.0 \mathrm{de}$ & $6.5 \mathrm{de}$ & $9.5 \mathrm{e}$ & $28.4 \mathrm{f}$ \\
\hline Az 21-day & $1.2 \mathrm{~cd}$ & $7.2 \mathrm{cde}$ & $19.8 \mathrm{~cd}$ & $4.4 \mathrm{~b}$ & $9.3 \mathrm{bcd}$ & $27.0 \mathrm{bc}$ & $8.1 \mathrm{bcd}$ & $10.5 \mathrm{e}$ & $32.8 \mathrm{de}$ \\
\hline Az+Pr 21-day & $0.6 \mathrm{~d}$ & $5.9 \mathrm{e}$ & $18.3 \mathrm{~cd}$ & $2.1 \mathrm{c}$ & $7.1 \mathrm{e}$ & $20.3 \mathrm{e}$ & $5.9 \mathrm{e}$ & $9.9 \mathrm{e}$ & 30.8 ef \\
\hline $\mathrm{Az}+\mathrm{Cl}$ 21-day & $0.6 \mathrm{~d}$ & $6.3 \mathrm{de}$ & $17.2 \mathrm{~d}$ & $5.4 \mathrm{~b}$ & $8.7 \mathrm{~cd}$ & $27.1 \mathrm{bc}$ & $6.1 \mathrm{e}$ & $10.2 \mathrm{e}$ & 30.8 ef \\
\hline $\mathrm{Pr}+\mathrm{Cl}$ 21-day & $4.0 \mathrm{a}$ & $15.1 \mathrm{a}$ & $38.0 \mathrm{a}$ & $7.8 \mathrm{a}$ & $16.3 \mathrm{a}$ & $43.7 \mathrm{a}$ & $9.3 \mathrm{~b}$ & $15.2 \mathrm{~b}$ & $43.2 \mathrm{~b}$ \\
\hline $\mathrm{Th}+\mathrm{Cl}$ 21-day & $4.5 \mathrm{a}$ & $15.6 \mathrm{a}$ & $39.1 \mathrm{a}$ & $7.7 \mathrm{a}$ & $16.3 \mathrm{a}$ & $43.2 \mathrm{a}$ & $11.6 \mathrm{a}$ & $14.6 \mathrm{bc}$ & $44.8 \mathrm{ab}$ \\
\hline Az 28-day & $2.4 \mathrm{bc}$ & $9.7 \mathrm{~b}$ & $25.8 \mathrm{~b}$ & $5.5 \mathrm{~b}$ & $10.8 \mathrm{~b}$ & $30.6 \mathrm{~b}$ & $9.3 \mathrm{~b}$ & $12.5 \mathrm{~d}$ & $36.6 \mathrm{~cd}$ \\
\hline $\mathrm{Az}+\operatorname{Pr} 28$-day & $2.4 \mathrm{bc}$ & $8.3 \mathrm{bcd}$ & $24.5 \mathrm{~b}$ & $4.7 \mathrm{~b}$ & $7.7 \mathrm{de}$ & $24.5 \mathrm{~cd}$ & $6.7 \mathrm{cde}$ & $10.7 \mathrm{e}$ & 34.3 cde \\
\hline $\mathrm{Az}+\mathrm{Cl}$ 28-day & $1.4 \mathrm{~cd}$ & $8.4 \mathrm{bc}$ & $20.7 \mathrm{c}$ & $5.3 \mathrm{~b}$ & $9.7 \mathrm{bc}$ & $30.4 \mathrm{~b}$ & $8.2 \mathrm{bc}$ & $13.4 \mathrm{~cd}$ & $38.2 \mathrm{c}$ \\
\hline $\mathrm{Pr}+\mathrm{Cl}$ 28-day & $4.3 \mathrm{a}$ & $14.4 \mathrm{a}$ & $36.2 \mathrm{a}$ & $7.5 \mathrm{a}$ & $16.5 \mathrm{a}$ & $42.7 \mathrm{a}$ & $9.6 \mathrm{~b}$ & $16.1 \mathrm{ab}$ & $43.8 \mathrm{ab}$ \\
\hline $\mathrm{Th}+\mathrm{Cl}$ 28-day & $3.8 \mathrm{ab}$ & $15.7 \mathrm{a}$ & $38.9 \mathrm{a}$ & $8.4 \mathrm{a}$ & $17.7 \mathrm{a}$ & $45.6 \mathrm{a}$ & $11.8 \mathrm{a}$ & $17.0 \mathrm{a}$ & $47.3 \mathrm{a}$ \\
\hline Control & $4.5 \mathrm{a}$ & $15.4 \mathrm{a}$ & $39.6 \mathrm{a}$ & $8.4 \mathrm{a}$ & $17.4 \mathrm{a}$ & $45.2 \mathrm{a}$ & $11.6 \mathrm{a}$ & $16.0 \mathrm{ab}$ & $46.6 \mathrm{ab}$ \\
\hline
\end{tabular}

${ }_{x}^{x}$ Numbers are the cumulative AUDPC values 4 weeks (21 August [Aug]), 8 weeks (24 September [Sep]), and 12 weeks (23 October [Oct]) after rust first developed on the nontreated control plants.

y Rust was assessed on a 0 -to- 5 rating scale, where $0=$ no lesions, $1=1$ to 20 lesions per leaf on old leaves, $2=>20$ lesions per leaf on old leaves, $3=1$ to 20 lesions per leaf on new leaves, $4=>20$ lesions per leaf on new leaves, and $5=>20$ lesions on every leaf (Dong et al. 2013). Data were then converted to AUDPC. Each datum set was analyzed using PROC MIXED at $P=0.05$.

${ }^{\mathrm{z}}$ Fungicide treatments included azoxystrobin $(\mathrm{Az})$ alone or combinations of azoxystrobin, propiconazole $(\mathrm{Pr})$, chlorothalonil $(\mathrm{Cl})$, and thiophanate methyl $(\mathrm{Th})$ at 14-, 21-, or 28-day applications. Control = nontreated control. 
(21 August, 24 September, and 23 October) after the first appearance of rust in all three fields (Table 1). AUDPC of the 14-day treatment was significantly lower than the 28-day treatment at all assessment dates, with the exception of 21 August (4 weeks after symptom development) in field 2. AUDPC values of the 21-day azoxystrobin treatments were typically intermediate between those of the 14- and 28-day azoxystrobin treatments. In general, disease increased with a longer application interval of azoxystrobin. The 21- and 28-day azoxystrobin treatments had significantly lower AUDPC compared with propiconazole + chlorothalonil or thiophanate methyl + chlorothalonil on all assessment dates. The AUDPC for the propiconazole + chlorothalonil and thiophanate methyl + chlorothalonil treatments at 21- and 28-day application intervals did not significantly differ from the nontreated control on the majority of the assessment dates at all locations.

When specific groups of fungicides were compared using linear contrasts, the AUDPC values of plants for the 14-day azoxystrobin treatment were consistently lower compared with the 21- and 28day treatments on all dates, with the exception of 21 August in field 2 (Table 2). AUDPC of 21-day treatments was consistently lower than 28-day treatments, with the exception of the 4-week AUDPC (21 August) in fields 1 and 2. Treatments containing azoxystrobin had lower AUDPC values than the four treatments not containing azoxystrobin. The AUDPC for treatments that included propiconazole, chlorothalonil, and thiophanate-methyl did not differ from that of the nontreated control (Table 2).

\section{Discussion}

Several fungicides are effective in managing daylily rust caused by the fungus $P$. hemerocallidis (Buck and Williams-Woodward 2003; Buck and Youmans 2009; Dong et al. 2013; Mueller et al. 2004). The four fungicides used in this study were selected because all are recommended for managing daylily rust when applied at 14-, 21-, and 28-day intervals (Williams-Woodward 2015). In the present study, azoxystrobin provided superior season-long rust control at all three spray intervals at three study locations.

Container nurseries typically spray large blocks of plant material at 21- or 28-day intervals. The blocks may include daylily cultivars that differ in their rust susceptibility or multiple plant species. Although disease management is of paramount concern for growers, spray practices are matters of economics and convenience. Professional recommendations include 18 different fungicides from six chemical classes: the quinone outside inhibitors (QoI, FRAC code 11), demethylation inhibitors (DMI, FRAC code 3), methyl benzimidazole carbamates (MBC, FRAC code 1) succinate dehydrogenase inhibitors (SDHI, FRAC code 7), chloronitriles (M5), and dithiocarbamates (M3) (Williams-Woodward 2015). Application interval recommendations vary from once a week to once a month and are predicated on the expected disease management outcome.

The level of disease tolerated by growers, hybridizers, and homeowners differs. Production nurseries will allow for low levels of disease because, in regards to disease, there are no protocols for determining whether or not a plant should be sold. In addition, it is too labor intensive to monitor low levels of disease given the large inventory of container nurseries (Dreistadt 2001). Typically, thousands of daylily plants in 5.7-liter nursery pots are packed tightly together into blocks of both resistant and susceptible varieties. Overhead irrigation is common and leaf moisture is often excessive. Collectively, these factors create the perfect environment for the development and spread of daylily rust: susceptibility, proximity, and free moisture. After plants have reached a certain size, they are shipped to ornamental wholesale and retail outlets across the country (Buck and Ono 2012). In the fall, daylily plants are commonly shipped as bare-root plants with much of their foliage removed. Infectious lesions or individual spores may be present but unseen between overlapping foliage at the base of the plant (Wise et al. 2004).

Given these circumstances and the cost of 7- and 14-day treatment intervals, container nurseries typically apply fungicides on 21- and 28 -day schedules. Our field study showed that azoxystrobin provided a significant disease reduction at 14-, 21-, and 28-day application intervals compared with propiconazole, chlorothalonil, or thiophanate-methyl. Azoxystrobin did not prove as effective in controlling daylily rust when applied at 28-day intervals compared with 14- and 21-day intervals. Nonetheless, disease was found in all treatments and no application interval or spray combination completely eliminated disease. Therefore, given the allowance of low-level disease, a 28-day application containing azoxystrobin would be acceptable for container nurseries; however, a 14- or 21-day application would be recommended.

According to the American Hemerocallis Society (www.daylilies. org), there are nearly 600 daylily hybridizers in the United States. Hybridizers operate on a smaller scale (fewer plants and smaller acreage) and typically require a higher level of disease management than container nurseries. Many of their cultivars may be new introductions with unknown levels of rust resistance (Mueller et al. 2003). Hybridizers ship plant selections to homeowners and other hybridizers and require that their plants be free of all disease before shipment. Therefore, hybridizers seek to eradicate daylily rust at their production facilities. No single treatment in our study eradicated daylily rust; even plants treated with azoxystrobin at 14-day intervals displayed some rust. Hybridizers would be well-advised to spray at 7-day intervals but efficacy data on this spray interval is needed. The level of disease management required by a homeowner will vary significantly. Homeowners are not shipping plants and they are not subject to any professional standards. Some disease, if noticed, will typically be tolerated.

Azoxystrobin provided the highest level of disease management in our study, and combining it with other fungicides did not enhance efficacy. Although our study examined the use of foliar sprays, prior work has shown azoxystrobin to be effective at managing daylily rust when applied as a soil drench and a root dip (Dong et al. 2013). Azoxystrobin belongs to the QoI class of fungicides (FRAC group 11), which inhibit cellular respiration. The active ingredients in this group are systemic or translaminar and broad spectrum, and are used as protectants, curatives, and eradicants (Bartlett et al. 2002; Vincelli 2002). Pyraclostrobin is another active ingredient in the same group that is effective at managing daylily rust when applied as

Table 2. $P$ values of single-degree-of-freedom linear contrasts of specific fungicide treatments to reduce daylily rust ${ }^{\mathrm{y}}$

\begin{tabular}{|c|c|c|c|c|c|c|c|c|c|}
\hline \multirow[b]{2}{*}{ Contrasts $^{\mathrm{z}}$} & \multicolumn{3}{|c|}{ Field 1} & \multicolumn{3}{|c|}{ Field 2} & \multicolumn{3}{|c|}{ Field 3} \\
\hline & 21 Aug & 24 Sep & 23 Oct & 21 Aug & 24 Sep & 23 Oct & 21 Aug & 24 Sep & 23 Oct \\
\hline Treatments & $<0.0001$ & $<0.0001$ & $<0.0001$ & $<0.0001$ & $<0.0001$ & $<0.0001$ & $<0.0001$ & $<0.0001$ & $<0.0001$ \\
\hline 11 trt vs. control & 0.0005 & $<0.0001$ & $<0.0001$ & 0.0008 & $<0.0001$ & $<0.0001$ & $<0.0001$ & $<0.0001$ & $<0.0001$ \\
\hline 14-day trt vs. 21 -day trt & 0.0283 & $<0.0001$ & $<0.0001$ & 0.0926 & $<0.0001$ & $<0.0001$ & 0.0105 & 0.0002 & $<0.0001$ \\
\hline 14-day trt vs. 28 -day trt & 0.0015 & $<0.0001$ & $<0.0001$ & 0.0090 & $<0.0001$ & $<0.0001$ & 0.0002 & $<0.0001$ & $<0.0001$ \\
\hline 21-day trt vs. 28 -day trt & 0.0529 & 0.0066 & 0.0012 & 0.0792 & 0.0110 & 0.0037 & 0.0132 & $<0.0001$ & 0.0003 \\
\hline $7 \mathrm{Az}$ trt vs. 4 trt without $\mathrm{Az}$ & $<0.0001$ & $<0.0001$ & $<0.0001$ & $<0.0001$ & $<0.0001$ & $<0.0001$ & $<0.0001$ & $<0.0001$ & $<0.0001$ \\
\hline 1 14-day Az vs. 3 21-day Az & 0.9573 & 0.6631 & 0.3070 & 0.5185 & 0.0035 & 0.0137 & 0.8076 & 0.2942 & 0.0603 \\
\hline Untrt vs. 4 non-Az trt & 0.5087 & 0.7653 & 0.2810 & 0.7859 & 0.2528 & 0.3130 & 0.1101 & 0.7039 & 0.2465 \\
\hline
\end{tabular}

y Treatments occurred in August (Aug), September (Sep), and October (Oct).

${ }^{\mathrm{z}}$ Contrasts $(P=0.05)$ were made between groups of treatments (trt): all 21-day trt, all 28-day trt, all trt including azoxystrobin $($ Az), and all trt without azoxystrobin; Untrt = untreated control. 
a foliar spray (Buck and Youmans 2009). In addition, azoxystrobin, pyraclostrobin, and two other QoI fungicides labeled for daylily rust, fluoxastrobin and trifloxystrobin, have been shown to significantly reduce urediniospore production by $P$. triticina and $P$. hemerocallidis (Buck et al. 2011).

With AUDPC values similar to the untreated control, propiconazole + chlorothalonil and thiophanate-methyl + chlorothalonil applied at 21- or 28-day intervals failed to protect daylily plants from rust. In addition, the latter fungicide treatments were ineffective when compared with azoxystrobin on each assessment date at all three locations. Propiconazole, a DMI, and thiophanate-methyl, an MBC, were equally ineffective in controlling daylily rust. Previously, Dong et al. (2013) noted that propiconazole was ineffective at managing daylily rust when applied at a 14-day interval, under high disease pressure. Likewise, thiophanate-methyl failed to affect urediniospore production by $P$. hemerocallidis when applied postinoculation (Buck et al. 2011). Nonetheless, both of these active ingredients are recommended for daylily rust at 21- and 28-day intervals. Our study has shown both of these systemic fungicides applied at these intervals to be ineffective at managing daylily rust under high disease pressure.

Chlorothalonil is a protectant fungicide and is more effective for managing daylily rust than propiconazole when applied as a foliar spray every 14 days (Dong et al. 2013). In addition, inhibition of urediniospore germination by chlorothalonil was similar to that of azoxystrobin and trifloxystrobin (Mueller et al. 2005). Because chlorothalonil has no systemic activity, it must be applied more frequently than systemic chemicals. It is typically used in combination and rotation with systemic fungicides; however, it had no effect on rust development in our study.

There is no definitive spray program for the management of daylily rust. Several active ingredients are recommended to be used from once a week to once a month. Growers could avoid unnecessary exposure and streamline chemical inventories by eliminating ineffective active ingredients. Two of the most commonly recommended fungicide active ingredients for management of daylily rust, propiconazole and thiophanate-methyl, failed to provide acceptable disease reductions when applied at 21- and 28-day intervals. Azoxystrobin provided acceptable disease control when applied at 28-day intervals and excellent disease control when applied at 14- and 21-day intervals. The QoI fungicide exhibited the highest level of management against $P$. hemerocallidis. Utilizing this class of active ingredients in rotation and combination with contact protectants such as chlorothalonil may provide growers with the most effective management of daylily rust. The FRAC classifies the QoI fungicides as being in the high-risk category for development of fungicide resistance in target populations and recommends a rotation with active ingredients with different modes of action. However, no practical control failures have been seen in the QoI group against Puccinia spp. (Schmitz et al. 2014). Thus, incorporation of QoI fungicides into management plans for daylily rust may reduce the development of resistance in $P$. hemerocallidis to other high-risk fungicide active ingredients.

\section{Acknowledgments}

We thank J. Davis for assistance with statistical analyses. This research was partially funded by the American Hemerocallis Society.

\section{Literature Cited}

Bartlett, D. W., Clough, J. M., Godwin, J. R., Hall, A. A., Hamer, M., and ParrDobrzanski, B. 2002. The strobilurin fungicides. Pest Manage. Sci. 58:649-662.

Buck, J. W. 2013. Identification of pathotypes in the daylily rust pathogen Puccinia hemerocallidis. Phytopathology 161:784-790.

Buck, J. W., and Ono, Y. 2012. Daylily rust. Online publication. Plant Health Instruct. doi:10.1094/PHI-I-2012-0516-01

Buck, J. W., Dong, W., and Mueller, D. S. 2010. Effect of light exposure on in vitro germination and germ tube growth of eight species of rust fungi. Mycologia 102:1134-1140.

Buck, J. W., and Williams-Woodward, J. L. 2003. The effect of fungicides on urediniospore germination and disease development of daylily rust. Crop Prot. 22:135-140.

Buck, J. W., Wise, K., and Dong, W. 2011. Effect of postsymptom application of fungicides on urediniospore production by Puccinia triticina on wheat and $P$. hemerocallidis on daylily. Plant Dis. 95:325-330.

Buck, J. W., and Youmans, J. 2009. Management of daylily rust with insignia pageant or trinity, 2007. Online publication. Plant Dis. Manage. Rep. 3:OT017.

Dong, W. B., Jeffers, S. N., and Buck, J. W. 2013. Management of daylily rust with different fungicides and application methods. Plant Dis. 97:921-926.

Dreistadt, S. H. 2001. Integrated Pest Management for Floriculture and Nurseries. Publ. 3402. Regents of the University of California, Division of Agriculture and Natural Resources, Oakland.

Gatlin, F. L. 1999. An Illustrated Guide to Daylilies, 2nd ed. The American Hemerocallis Society, Inc., Kansas City, MO.

Mueller, D. S., Jeffers, S. N., and Buck, J. W. 2004. Effect of timing of fungicide applications on development of rusts on daylily, geranium, and sunflower. Plant Dis. 88:657-661

Mueller, D. S., Jeffers, S. N., and Buck, J. W. 2005. Toxicity of fungicides to urediniospores of six rust fungi that occur on ornamental crops. Plant Dis. 89: 255-261.

Mueller, D. S., Williams-Woodward, J. L., and Buck, J. W. 2003. Resistance of daylily cultivars to the daylily rust pathogen, Puccinia hemerocallidis. HortScience 38:1137-1140.

Schmitz, H. K., Medeiros, C. A., Craig, I. R., and Stammler, G. 2014. The sensitivity of Phakopsora pachyrhizi towards quinone-outside-inhibitors and demethylation-inhibitors, and corresponding resistance mechanisms. Pest Manage. Sci. 70:378-388.

United States Department of Agriculture. 2014. Floriculture Crops, 2013 Summary. National Agriculture Statistics Services. Online publication. http://www. nass.usda.gov/Statistics_by_State/New_Jersey/Publications/Floriculture_ Statistics/FlorCrop-06-19-2014.pdf

Vincelli, P. 2002. 2002. $\mathrm{Q}_{\mathrm{o}} \mathrm{I}$ (Strobilurin) Fungicides: Benefits and Risks. Online publication. Plant Health Instruct. Updated 2012. doi:10.1094/PHI-I-2002-0809-02

Williams-Woodward, J. L. 2015. Ornamentals and shade tree disease control Part B Plant use index. Pages 80-83 in: Georgia Pest Management Handbook-2015 Commercial Edition. D. Horton, ed. Online publication. UGA Extension. http://extension.uga.edu/publications/detail.cfm?number=SB28

Williams-Woodward, J. L., and Buck, J. W. 2002. Diseases and pests of daylily. Pages 222-229 in: New Daylily Handbook. F. Gatlin, and J. Brennan, eds. American Hemerocallis Society, Inc., Kansas City, MO.

Williams-Woodward, J. L., Hennen, J. F., Parda, K. W., and Fowler, J. M. 2001. First report of daylily rust in the United States. Plant Dis. 85:1121.

Wise, K. A., Mueller, D. S., and Buck, J. W. 2004. Quarantines and ornamental rusts. Online publication. APSnet Features. doi:10.1094/APSnetFeature2004-0204 